\title{
CFD-DEM and Experimental Study of Bubbling in a Fluidized Bed
}

\author{
Hassan A. Khawaja \\ Reprinted from

\section{The Journal of Computational Multiphase Flows}

Volume 7 - Number $4 \cdot 2015$ 


\title{
CFD-DEM and Experimental Study of Bubbling in a Fluidized Bed
}

\author{
Hassan A. Khawaja* \\ Department of Engineering and Safety, UiT - The Arctic University of Norway
}

Received: 1 May 2015; Accepted: 11 November 2015

\begin{abstract}
In this study, phenomenon of bubbling is investigated using CFD-DEM and experiments. A CFD-DEM simulation is setup to model the fluidized beds of different sizes. Geldart D particles of $1.2 \mathrm{~mm}$ diameter and $1000 \mathrm{Kg} / \mathrm{m}^{3}$ density are modelled. Study revealed different types of fluidization regimes as stated in the literature. An experimental setup is built to obtain the results for the comparison. Comparison revealed that results obtained from both methodologies; CFD-DEM and experiments are in reasonable agreement.
\end{abstract}

\section{INTRODUCTION}

In a fluidized bed, fluid is passed through a bed of solid particles. If the fluid velocity is sufficiently high, the drag force exerted by the fluid on the particles will equal the total weight of the particles in the bed. At this point, particles can move freely and the bed behaves like a liquid. Depending on the fluid velocity, the particle diameter, the fluid and particle densities and the bed dimensions, different fluidisation regimes can be observed [1]. In this work, the phenomenon of bubbling in fluidized bed is examined in particular. The phenomenon of bubbling in a fluidized bed is one of the regimes of fluidization as given in [2]. It has been defined as a form of aggregative fluidization by [1]. [3] gave the relationship for bubble velocity in an inviscid liquid as shown in Equation (1),

$$
U_{B}=0.71 \sqrt{g D_{B}}
$$

where $U_{B}$ is the bubble velocity, $g$ is the gravity constant and $D_{B}$ is the volumetric equivalent diameter of bubble. [4] gave the relationship for the slug (also known as square nosed bubbles) velocity in a fluidized bed as shown in Equation (2),

$$
U_{S}=0.35 \sqrt{g D_{T}}
$$

where $U_{S}$ is the slug velocity, $g$ is the gravity constant and $D_{T}$ is the volumetric equivalent diameter of channel. [5] proposed that slugs attached to wall move about 1.4 times faster than the normal slugs. Also, in the case of continuous bubbling, [1], [6], and [7] argued that the difference in the superficial fluid velocity and the minimum fluidization velocity must be added to the bubble and slug velocities. The modified equations are shown in Equations (3) and (4),

$$
\begin{aligned}
& U_{B}=U-U_{m f}+0.71 \sqrt{g D_{B}} \\
& U_{S}=U-U_{m f}+0.35 \sqrt{g D_{T}}
\end{aligned}
$$

where $U$ is the superficial velocity of fluid in the fluidized bed and $U_{m f}$ is the minimum fluidization velocity.[8] gave the rise velocity of bubble in two dimensional systems as shown in Equation (5),

$$
U_{B}=U-U_{m f}+0.5 \sqrt{g D_{B_{-} 2 D}}
$$


where $D_{B 2 D}$ is the diameter of equivalent circular bubble in 2-D.

The frequency of bubbling at various heights above distributor has been studied by various researchers as shown in Figure 1. The frequency at which bubbles pass a probe falls with height above the distributor due to coalescence.

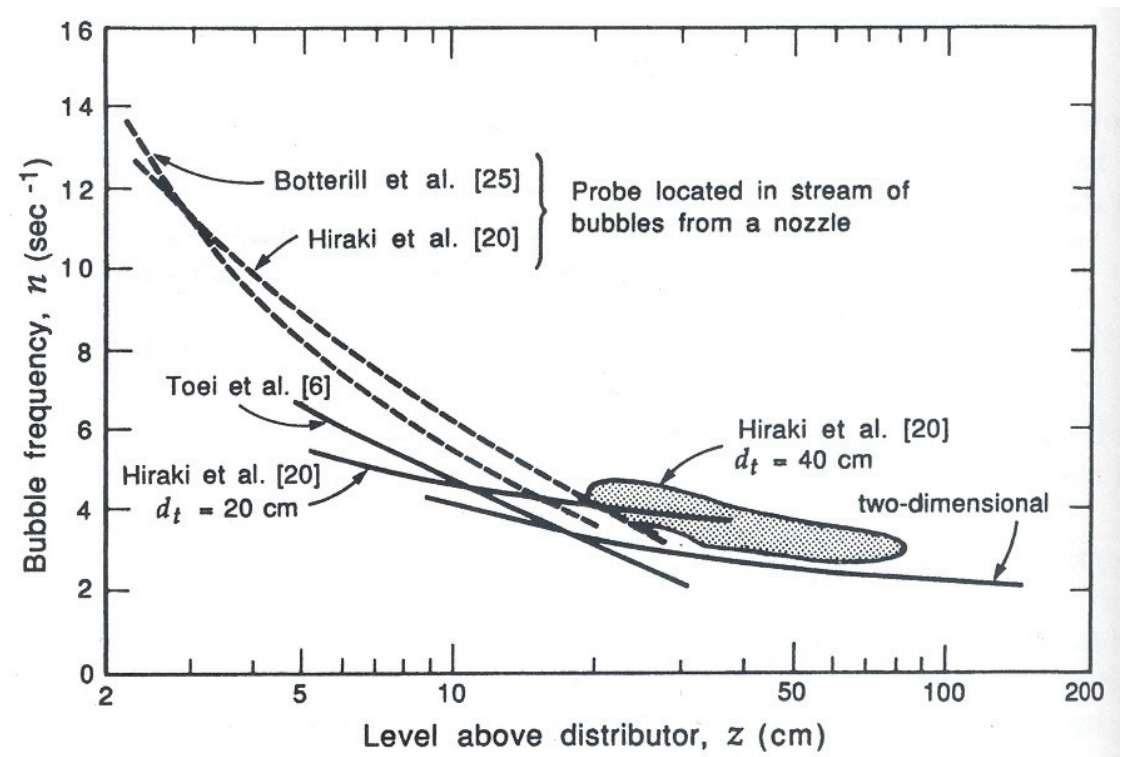

Figure 1: Bubbling frequency $(\mathrm{Hz})$ above distributor $(\mathrm{cm})$ (Reproduced from [2])

A fluidized bed can either begin bubbling immediately after minimum fluidization is reached or it can expand as the superficial velocity is increased before experiencing bubbling. Whether or not bubbling occurs immediately when the bed is fluidized or after expansion is dependent on particle size and the densities of the fluid and particles as explained by [2] and [1]. Particles are categorised in Geldart groups based on their size range as given by [9]. It is widely accepted in literature that Geldart D (diameter $\approx 1.2 \mathrm{~mm}$ and density $=1000 \mathrm{Kg} / \mathrm{m}^{3}$ ) particles undergo bubbling immediately after fluidization. In this work, only Geldart $\mathrm{D}$ particles are considered. The particle size has been kept in Geldart D grouping because given CFD-DEM computational model was not modified to simulate the adhesive effects. Adhesive forces become very important in fluidized beds with smaller particles, and their modelling requires incorporation of adhesive forces.

In this work, the CFD-DEM numerical simulation is used to model bubbling in fluidized beds. In order to verify the CFD-DEM results, an experiment technique is established. With the use of imaging process techniques via [10], results are post processed and compared. The focus has been put on frequency of bubbling and expansion of the bed. Finally, results are compared with the experiments to validate the accuracy of the CFD-DEM computational model.

\section{CFD-DEM MODEL}

In this work, the volume-averaged continuity and momentum equations (Equations (6) and (7)) are solved using CFD (computational fluid dynamics) density driven method [11, 12].

$$
\begin{gathered}
\frac{\partial(\rho \epsilon)}{\partial t}+\frac{\partial\left(\rho \epsilon u_{k}\right)}{\partial x_{k}}=0 \\
\frac{\partial\left(\rho \epsilon u_{i}\right)}{\partial t}+\frac{\partial\left(\rho \epsilon u_{i} u_{k}\right)}{\partial x_{k}}=\frac{\partial}{\partial x_{k}} \epsilon p+\frac{\partial}{\partial x_{k}} \cdot \epsilon \tau_{f}-\vec{F}_{i}+\rho \epsilon g_{i}
\end{gathered}
$$

Where $\in$ is the voidage, $\rho$ is the density fluid and $u_{k}$ is the velocity of the fluid, $p$ is the pressure of 
the fluid, $\overrightarrow{\mathrm{F}}_{i}$ is the interaction force felt by the fluid due to the particles, $g_{i}$ is the gravity constant and $\tau_{f}$ is the fluid stress tensor. Note that and subscripts are Einstein notations [11]. Voidage $\in$ is the ratio of volume of fluid (excluding the particles) to the total volume of a fluid cell. It needs to be accurately computed in cuboidal domain of CFD with moving spherical particles as given by [13].

The finite volume discretisation technique is applied to the Equations (6) and (7). This technique is based on conservation of variables therefore; it ensures that the physical quantities are conserved over the chosen control volumes, and the domain as a whole [14, 15].

The stability and sensitivity of the solution depends on the time step and cell size. The time step and cell size values are determined by Courant-Friedrichs-Lewy (CFL) condition $[16,17]$ as shown in Equation (8).

$$
C F L \text { Number }>\frac{a \Delta t}{\min (\Delta x, \Delta y, \Delta z)}
$$

Where $\Delta t$ is the time step size, $\Delta x, \Delta y, \Delta z$ are the dimensions of the fluid cell and $a$ is the speed of sound in the gas medium.

The interaction force correlations are given by [18-21]. [22] compared these correlations by conducting fluidized bed experiments and found that [21] is most promising in the voidage range of $0.3<\epsilon<0.5$. This correlation is shown in Equation (9).

$$
\beta=A \frac{(1-\epsilon) \mu_{f}}{\epsilon d_{p}^{2}}+B \frac{\mu_{f}(1-\epsilon) R e}{d_{p}^{2}}
$$

Where $\beta$ is the drag coefficient, $A$ is shown in Equation (10) and $\beta$ is shown in Equation (11).

$$
\begin{gathered}
A=180+\frac{18 \epsilon^{4}}{1-\epsilon}(1+1.5 \sqrt{(1-\epsilon)}) \\
B=\frac{0.31\left(\epsilon^{-1}+3 \epsilon(1-\epsilon)+8.4 R e^{-0.343}\right)}{1+10^{3(1-\epsilon)} \operatorname{Re}^{2 \epsilon-2.5}}
\end{gathered}
$$

In CFD-DEM simulations, the interaction force felt by the fluid due to the particles is the sum of the drag on the particles in the particular fluid cell as shown in Equation (12).

$$
\overrightarrow{F_{i}}=\frac{1}{(1-\epsilon) V_{\text {cell }}} \sum_{i=1}^{n_{p}} \vec{f}_{i}
$$

Where $V_{\text {cell }}$ is the volume of the cell, $n_{p}$ is the number of particles in the cell, $\vec{f}_{l}$ is the drag force on $i$ particle as shown in Equation (13).

$$
\overrightarrow{f_{i}}=V_{p} \beta\left(\vec{u}_{f}-\vec{u}_{p}\right)
$$

Where $\vec{f}_{l}$ is the force vector felt by the particle due to the fluid drag, $V_{p}$ is the volume of the particle and $\beta$ is the drag coefficient computed using correlation given in Equation (9).

Discrete element modelling (DEM) is based on a Lagrangian approach where each particles motion is governed by Newton's second law. The linear momentum equation for each particle is, 


$$
m_{p} \vec{a}_{p}=\vec{f}_{i}+\sum_{\text {contacts }} \vec{f}_{\text {contacts }}+m_{p} \vec{g}
$$

where $m_{p}$ is the mass of the particle, $\vec{a}_{p}$ is the linear acceleration vector, $\vec{f}_{i}$ is the force on the particles due to the fluid, $\vec{f}_{\text {contact }}$ is the force due to contacts with other particles and the sum is over all contacts acting on particle.

The 3rd order Adams-Bashforth time stepping scheme [23, 24] as shown in Equation (15) is used to advance the fluid as well as particle variables forward in time.

$$
P_{t+1}=P_{t}+\Delta t\left(\frac{23}{12} d P_{t+1}-\frac{4}{3} d P_{t}+\frac{5}{12} d P_{t-1}\right)
$$

Where $\Delta t$ is the time step size, $P_{\mathrm{t}+1}$ is the value of the physical property stepping forward in time, $P_{t}$ is the value of the physical property before stepping forward in time, $d P$ is the change in the property. The subscript in Equation (15) refer to time step.

Particle-particle contact is solved using soft sphere contact models $[12,25]$. In the soft contact model, the contact forces are based on simple linear springs and dashpot model, where contact forces are the function of particles' displacement and velocity. These models has been used in DEM by [12, 26-30]. The contact forces can be divided into normal and tangential forces. Normal contact model is based on non-linear spring model given by Hertz [31]. Tangential contact model is given by [32] and simplified by [28] for DEM. Both models is tested for their suitability for DEM by [33].

Most computationally intensive operation in CFD-DEM simulation is the search of particleparticle contacts. [34] has given a study on optimisation of this algorithm.

Given CFD-DEM model has been used for fluidized bed studies in [35-37].

\section{CFD-DEM SETUP}

The system studied here is a two-dimensional fluidized bed. The dimensions of the domain and grid distribution of configuration B (Figure 3) is shown in Figure 2. This configuration consists of 9240 particles with an un-fluidized bed height of $30 \mathrm{~mm}$ approximately. The simulation is three dimensional as far as the particles are concerned, but two dimensional for the fluid flow (there is only one active fluid cell in the z-direction). The side walls were frictional surfaces with the same material properties as for the particles, whilst the z-faces were taken to be frictionless. The pseudo 2-D simulations were performed because it makes the flow structures readily observable.

The inlet flow velocity was controlled by manipulating the rate of change of mass flux through the lower horizontal boundary. Fluid flow velocity was increased by setting the rate of change of mass flux to the point where (fluid superficial velocity/minimum fluidisation velocity) equals to 2.0 , at which point the superficial velocity was kept constant for about $10 \mathrm{~s}$. The configurations simulated using the above mentioned conditions are shown in Figure 3.

A density driven method was used, with a non-reflecting boundary condition specified at the outlet. The computational method is parallelized to run for a larger case (configuration G), where the number of particles was 147480 . The simulated particle size and density is same as that of poppy seeds (diameter $=1.2 \mathrm{~mm}+/-0.15 \mathrm{~mm}$ and density of $1000 \mathrm{Kg} / \mathrm{m} 3$ ), which were used to perform the experiments. The parameters set for simulating the different configurations are given in Table 1. 

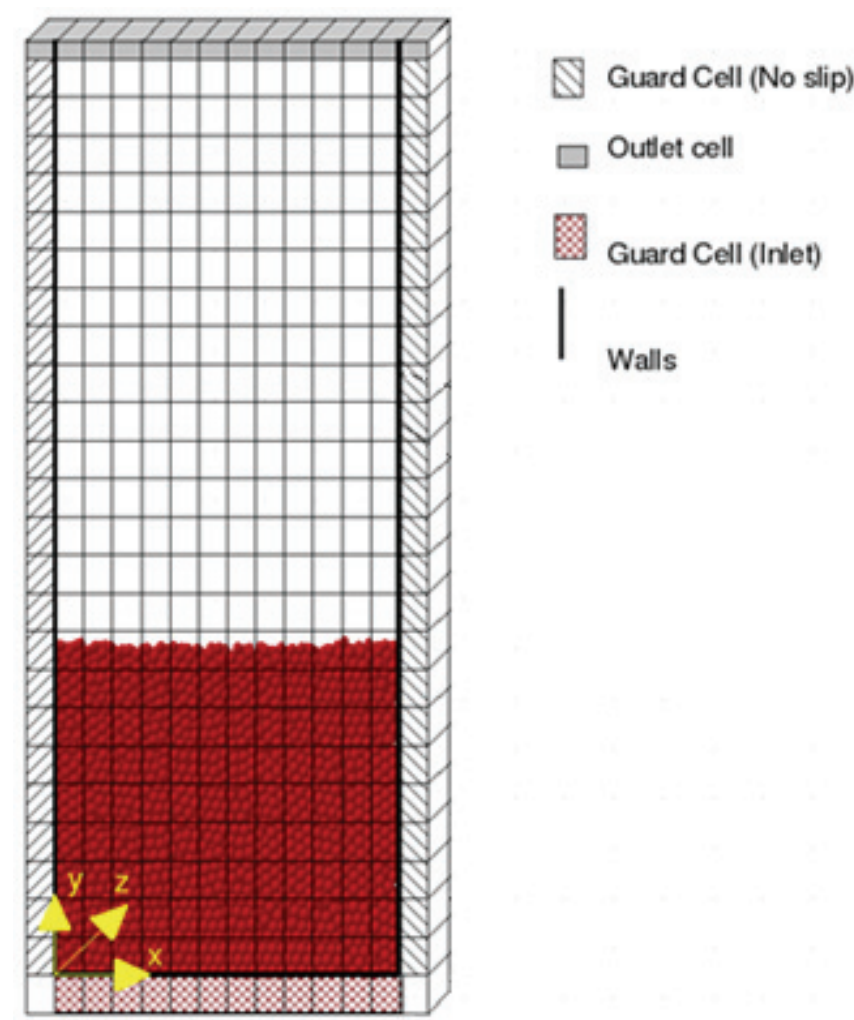

Figure 2: CFD-DEM numerical simulations of a fluidized bed; this figure shows the configuration $\mathrm{B}$ as shown in Figure 3

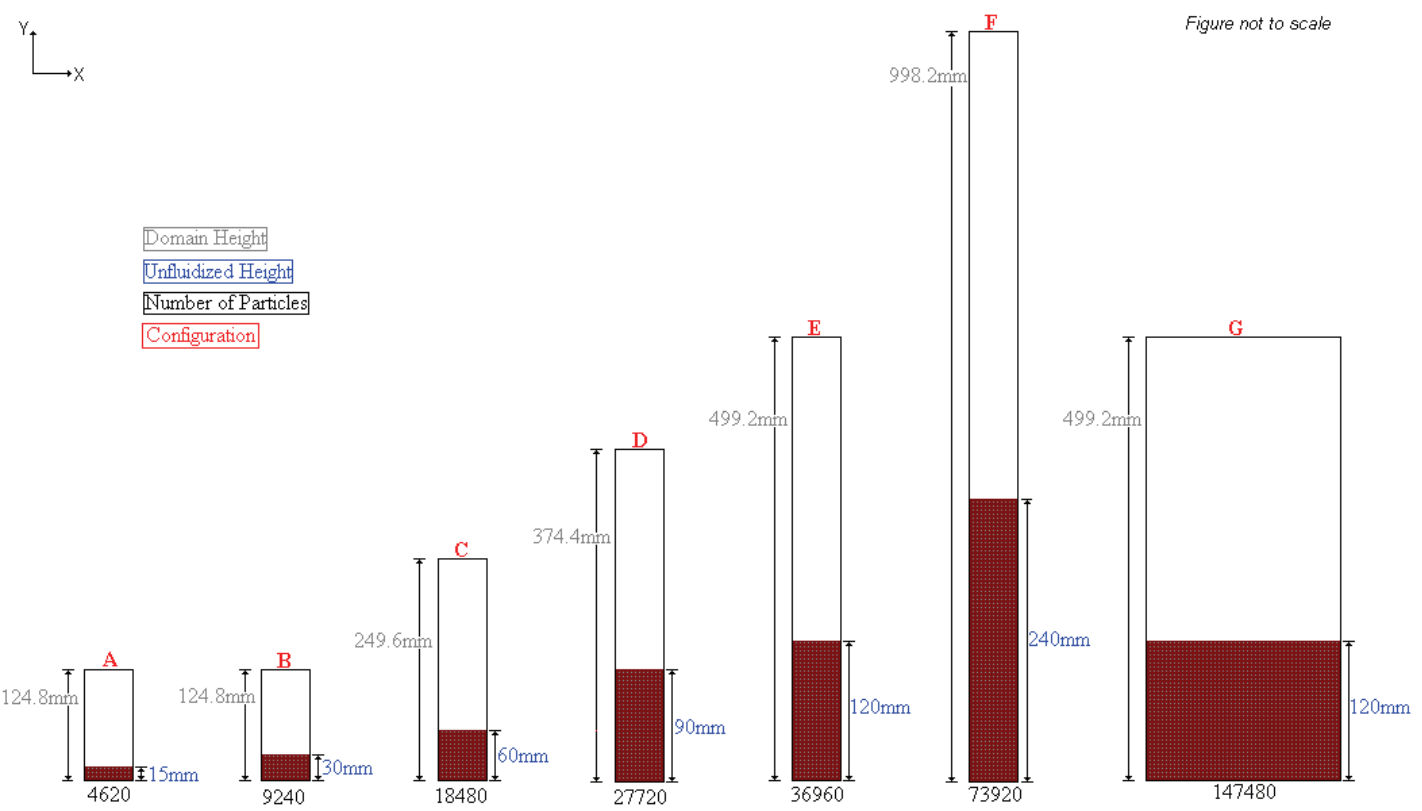

Figure 3: The simulated beds. The un-fluidized heights of the beds and the total heights of the domains are shown. The number under the bed gives the total number of particles. Alphabetical letter refers to the particular configuration. 
Table 1: Parameters for CFD-DEM simulation of fluidized bed as per the configuration shown in Figure 2

\begin{tabular}{|c|c|c|c|c|c|c|c|}
\hline Parameters & $A$ & $B$ & $C$ & $D$ & $E$ & $F$ & $\begin{array}{c}G \\
\text { (Parallel) }\end{array}$ \\
\hline $\begin{array}{l}\text { Bed Width (x- } \\
\text { direction) }\end{array}$ & $0.0432 \mathrm{~m}$ & $0.0432 \mathrm{~m}$ & $0.0432 \mathrm{~m}$ & $0.0432 \mathrm{~m}$ & $0.0432 \mathrm{~m}$ & $0.0432 \mathrm{~m}$ & $0.1728 \mathrm{~m}$ \\
\hline $\begin{array}{l}\text { Bed Height (y- } \\
\text { direction) }\end{array}$ & $0.0624 \mathrm{~m}$ & $0.1248 m$ & $0.2496 \mathrm{~m}$ & $0.3744 \mathrm{~m}$ & $0.4992 m$ & $0.9984 \mathrm{~m}$ & $0.4992 m$ \\
\hline $\begin{array}{c}\text { Bed Thickness (z- } \\
\text { direction) }\end{array}$ & $0.01 \mathrm{~m}$ & $0.01 \mathrm{~m}$ & $0.01 \mathrm{~m}$ & $0.01 \mathrm{~m}$ & $0.01 \mathrm{~m}$ & $0.01 \mathrm{~m}$ & $0.01 \mathrm{~m}$ \\
\hline $\begin{array}{l}\text { Total Number of } \\
\text { Fluid Cells }\end{array}$ & $\begin{array}{c}14 \times 26 \times \\
1\end{array}$ & $\begin{array}{c}14 \times 26 \times \\
1\end{array}$ & $\begin{array}{c}14 \times 52 \times \\
1\end{array}$ & $\begin{array}{c}14 \times 78 \times \\
1\end{array}$ & $\begin{array}{c}14 \times 104 \times \\
1\end{array}$ & $\begin{array}{c}14 \times 208 \times \\
1\end{array}$ & $\begin{array}{c}56 \times 104 \times \\
1\end{array}$ \\
\hline Fluid Cell Size & $\begin{array}{c}3.6 \mathrm{~mm} \times \\
4.8 \mathrm{~mm} \times \\
10 \mathrm{~mm}\end{array}$ & $\begin{array}{c}3.6 \mathrm{~mm} \mathrm{x} \\
4.8 \mathrm{~mm} \mathrm{x} \\
10 \mathrm{~mm}\end{array}$ & $\begin{array}{c}3.6 \mathrm{~mm} x \\
4.8 \mathrm{~mm} \times \\
10 \mathrm{~mm}\end{array}$ & $\begin{array}{c}3.6 \mathrm{~mm} x \\
4.8 \mathrm{~mm} x \\
10 \mathrm{~mm}\end{array}$ & $\begin{array}{c}3.6 \mathrm{~mm} \times \\
4.8 \mathrm{~mm} \times \\
10 \mathrm{~mm}\end{array}$ & $\begin{array}{c}3.6 \mathrm{~mm} \mathrm{x} \\
4.8 \mathrm{~mm} \mathrm{x} \\
10 \mathrm{~mm}\end{array}$ & $\begin{array}{c}3.6 \mathrm{~mm} x \\
4.8 \mathrm{~mm} x \\
10 \mathrm{~mm}\end{array}$ \\
\hline $\begin{array}{l}\text { Total Number of } \\
\text { DEM Cells }\end{array}$ & $\begin{array}{c}44 \times 95 \times \\
20\end{array}$ & $\begin{array}{c}44 \times 95 \times \\
20\end{array}$ & $\begin{array}{c}44 \times 190 \times \\
20\end{array}$ & $\begin{array}{c}44 \times 285 \times \\
20\end{array}$ & $\begin{array}{c}44 \times 380 \times \\
20\end{array}$ & $\begin{array}{c}44 \times 760 \times \\
20\end{array}$ & $\begin{array}{c}144 \times 358 \\
\times 21\end{array}$ \\
\hline Nominal Pressure & 1 bar & 1 bar & 1 bar & 1 bar & 1 bar & 1 bar & 1 bar \\
\hline Temperature & $298.15 K$ & $298.15 K$ & $298.15 K$ & $298.15 K$ & $298.15 K$ & $298.15 K$ & $298.15 K$ \\
\hline Fluid Density & $\begin{array}{c}1.13 \\
K g / m^{3}\end{array}$ & $\begin{array}{c}1.13 \\
K g / m^{3}\end{array}$ & $\begin{array}{c}1.13 \\
K g / m^{3}\end{array}$ & $\begin{array}{c}1.13 \\
K g / m^{3}\end{array}$ & $\begin{array}{c}1.13 \\
K g / m^{3}\end{array}$ & $\begin{array}{c}1.13 \\
K g / m^{3}\end{array}$ & $\begin{array}{c}1.13 \\
K g / m^{3}\end{array}$ \\
\hline Time Step Size & $\begin{array}{c}2.6 \times 10^{-6} \\
\text { sec }\end{array}$ & $\begin{array}{c}2.6 \times 10^{-6} \\
\text { sec }\end{array}$ & $\begin{array}{c}2.6 \times 10^{-6} \\
\text { sec }\end{array}$ & $\begin{array}{c}2.6 \times 10^{-6} \\
\text { sec }\end{array}$ & $\begin{array}{c}2.6 \times 10^{-6} \\
\sec \end{array}$ & $\begin{array}{c}2.6 \times 10^{-6} \\
\text { sec }\end{array}$ & $\begin{array}{c}2.6 \times 10^{-6} \\
\text { sec }\end{array}$ \\
\hline $\begin{array}{l}\text { Number of } \\
\text { Particles }\end{array}$ & 4620 & 9240 & 18480 & 27720 & 36960 & 73920 & 147480 \\
\hline Size of Particles & $\begin{array}{c}1.2 \pm \\
0.05 \mathrm{~mm}\end{array}$ & $\begin{array}{c}1.2 \pm \\
0.05 \mathrm{~mm}\end{array}$ & $\begin{array}{c}1.2 \pm \\
0.05 \mathrm{~mm}\end{array}$ & $\begin{array}{c}1.2 \pm \\
0.05 \mathrm{~mm}\end{array}$ & $\begin{array}{c}1.2 \pm \\
0.05 \mathrm{~mm}\end{array}$ & $\begin{array}{c}1.2 \pm \\
0.05 \mathrm{~mm}\end{array}$ & $\begin{array}{c}1.2 \pm \\
0.05 \mathrm{~mm}\end{array}$ \\
\hline Particle Density & $\begin{array}{c}1000 \\
K g / m^{3}\end{array}$ & $\begin{array}{c}1000 \\
K g / m^{3}\end{array}$ & $\begin{array}{c}1000 \\
K g / m^{3}\end{array}$ & $\begin{array}{c}1000 \\
K g / m^{3}\end{array}$ & $\begin{array}{c}1000 \\
K g / m^{3}\end{array}$ & $\begin{array}{c}1000 \\
\mathrm{Kg} / \mathrm{m}^{3}\end{array}$ & $\begin{array}{c}1000 \\
K g / m^{3}\end{array}$ \\
\hline $\begin{array}{c}\text { Young Modulus of } \\
\text { Particles }\end{array}$ & $\begin{array}{c}1.2 \times 10^{8} \\
\mathrm{~Pa}\end{array}$ & $\begin{array}{c}1.2 \times 10^{8} \\
\mathrm{~Pa}\end{array}$ & $\begin{array}{c}1.2 \times 10^{8} \\
\mathrm{~Pa}\end{array}$ & $\begin{array}{c}1.2 \times 10^{8} \\
\mathrm{~Pa}\end{array}$ & $\begin{array}{c}1.2 \times 10^{8} \\
\mathrm{~Pa}\end{array}$ & $\begin{array}{c}1.2 \times 10^{8} \\
\mathrm{~Pa}\end{array}$ & $\begin{array}{c}1.2 \times 10^{8} \\
\mathrm{~Pa}\end{array}$ \\
\hline Poisson Ratio & 0.3 & 0.3 & 0.3 & 0.3 & 0.3 & 0.3 & 0.3 \\
\hline $\begin{array}{c}\text { Coefficient of } \\
\text { Normal Restitution }\end{array}$ & 0.986 & 0.986 & 0.986 & 0.986 & 0.986 & 0.986 & 0.986 \\
\hline $\begin{array}{l}\text { Coefficient of } \\
\text { Friction }\end{array}$ & 0.1 & 0.1 & 0.1 & 0.1 & 0.1 & 0.1 & 0.1 \\
\hline
\end{tabular}

\section{EXPERIMENTAL SETUP}

In order to verify the CFD-DEM results obtained via simulation, two experimental systems were constructed. The first has the same width and depth as that shown in Figure 2, and could be filled to different levels to give un-fluidized heights which matched the simulations. The experimental setup used in the experiments is shown in Figure 4. A second, wider, experimental system was constructed in the same way, but with a width to match the width of wider simulation (shown as configuration $\mathrm{G}$ in Figure 2).

The beds are made of Perspex. The distributor for smaller bed (width wise) was made using Perspex with a total of $170.5 \mathrm{~mm}$ holes placed in a diagonal pattern with a distance of $1.0 \mathrm{~cm}$ in total between holes. For the wider bed, the distributor was an aluminium plate with a total of about $402 \mathrm{~mm}$ holes arranged in a diagonal pattern. It was noted in the early experimental stages that air 
jets were forming a voidage right above the distributor as shown in Figure 5. In order to provide a uniform flow to the bed, a piece of foam is put in to prevent jet effects. Air was supplied from a compressor, regulated to 1 bar atmospheric, with flow rate measured by a calibrated flow meter. The air superficial velocity entering the in the bed was $0.66 \mathrm{~m} / \mathrm{s}$ (about two times the minimum fluidization velocity of the poppy seeds).

A camera (DCR-HC14E Sony Handy cam) was used to record the motion of the bubbles in the bed. A white background was placed behind the bed to provide a contrast to the poppy seeds which are dark gray in colour. The colour difference was later used to identify the bubbles (voids).

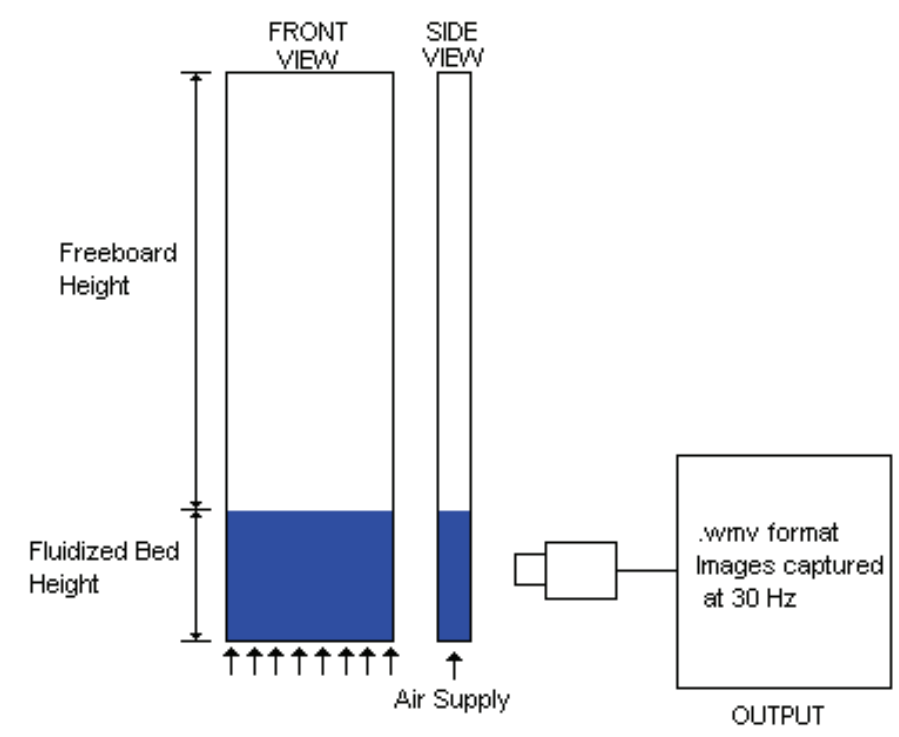

Figure 4: Experimental setup for the study of bubbling bed
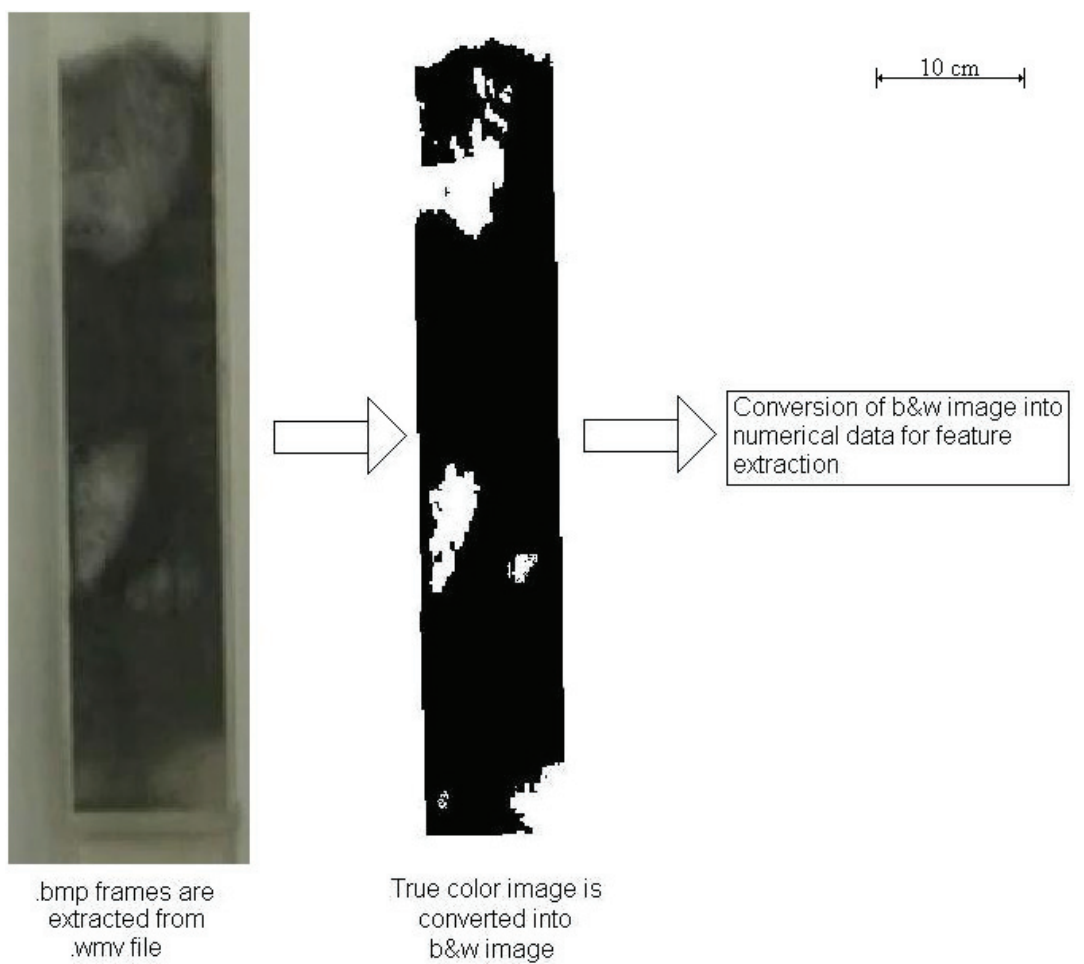

Figure 5: The conversion of .bmp file into black and white (b \& w) image for post processing of bubbling bed results; voids can be seen right above the distributor (jet effects) 
The camera recorded a .wmv clip with a frame rate of $30 \mathrm{~Hz}$. Although the camera effectively records the voidage in the bed, the exact voidage values were difficult to obtain from the images. Since the bed was bubbling, it was expected that the voidage around the bubbles was approximately constant (equal to that at minimum fluidization $\left(\epsilon_{m f}\right)$ ). The bubbles can clearly be seen from the images as regions with voidage much lower than, $\epsilon_{m f}$ and can be tracked as they move up the bed. To locate the bubbles, each frame from the video was converted into a black and white image (with a binary gate) using image processing toolbox of Matlab® as shown in Figure 5. These black and which images could then be further analysed as required. In order to measure the pressure behaviour along the bed, pressure sensors were deployed at $5 \mathrm{~cm}$ intervals above the distributor. A pressure signal was taken through the PX138-0.3D5V sensors using Data Acquisition Card (Measurement Computing ${ }^{\mathrm{TM}}$ USB-1208LS) and recorded in a computer. The extracted data was recorded in volts and was then converted into Pascals using a calibration curve. Finally, this data was post-processed in [10] for further analysis.

\section{CFD-DEM RESULTS}

A total of 8 different configurations were simulated as shown in Figure 3. Results from 3 cases, B, $\mathrm{E}$ and $\mathrm{G}$ are discussed below. The snapshots of voidage fields were taken at different times in order to identify the formation of bubble(s), their coalescence and their eruption as shown in figures Figure 6, Figure 7 and Figure 8.

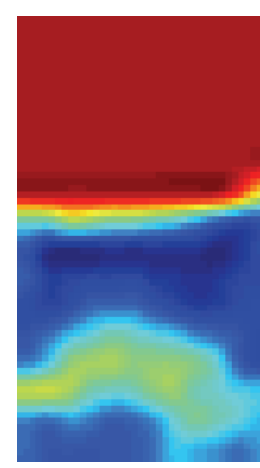

$0 \mathrm{~s}$

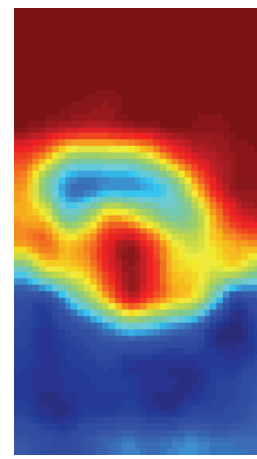

$0.195 \mathrm{~s}$

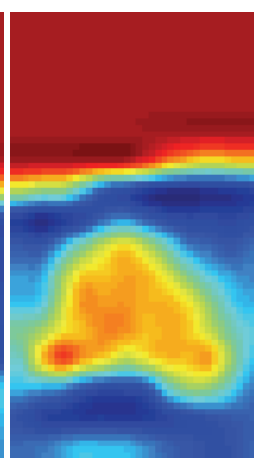

$0.039 \mathrm{~s}$

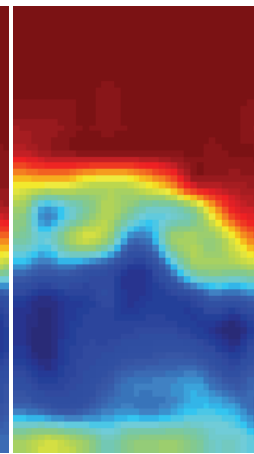

$0.234 \mathrm{~s}$

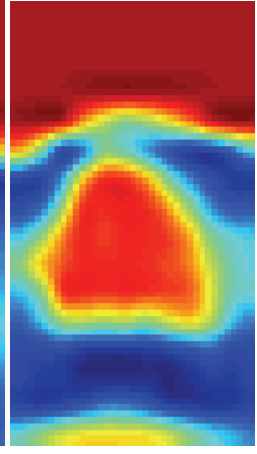

$0.078 \mathrm{~s}$

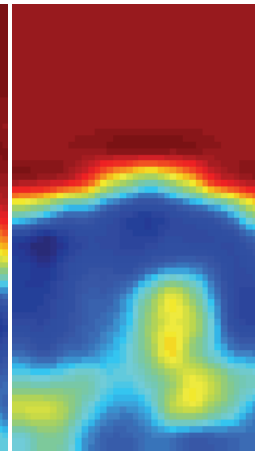

$0.273 \mathrm{~s}$
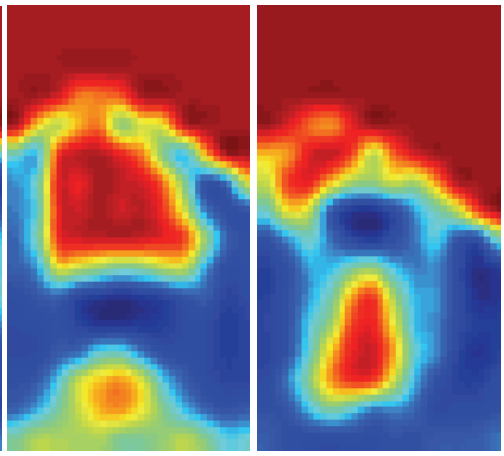

$0.117 \mathrm{~s}$

$0.156 \mathrm{~s}$

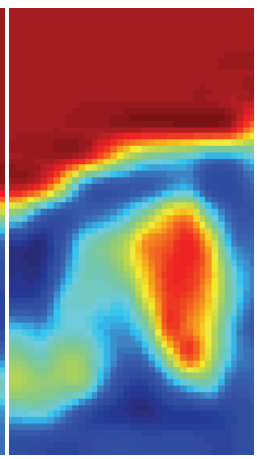

$0.312 \mathrm{~s}$

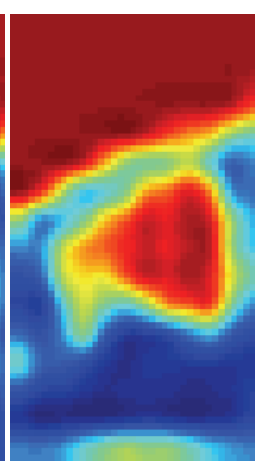

$0.351 \mathrm{~s}$

Figure 6: Voidage field for configuration (B) bed height $=15 \mathrm{~mm}$ (9240 particles) at $U / U_{m f}=2.0$; bubble appearance $(0.039 \mathrm{~s})$ and bubble eruption (0.195 s) are identifiable; red colour shows completely void regions, blue and intermediate shades shows the 2

phase medium with dark blue being the most densely packed with particles

In smaller beds (configurations A, B and C), only a single bubble is present in the bed at any given time because before a $2^{\text {nd }}$ bubble can form, the $1^{\text {st }}$ bubble erupts and disappears, as demonstrated in Figure 6. Figure 7 shows the voidage field for configuration $\mathrm{E}$ to demonstrate the bubbling phenomenon in deeper beds. 


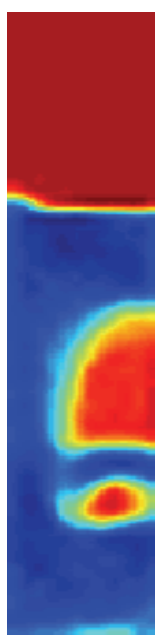

$0 \mathrm{~s}$

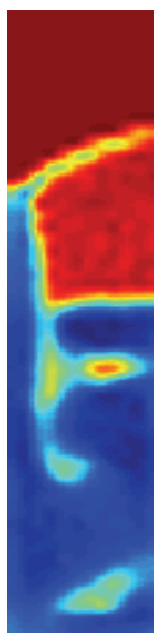

$0.195 \mathrm{~s}$
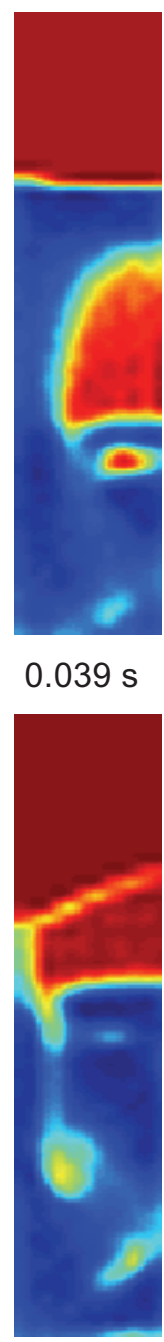

$0.234 \mathrm{~s}$

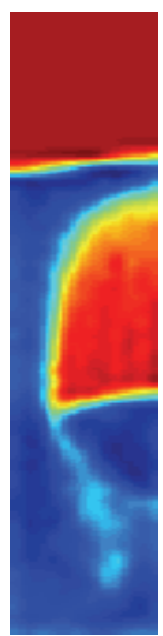

$0.078 \mathrm{~s}$

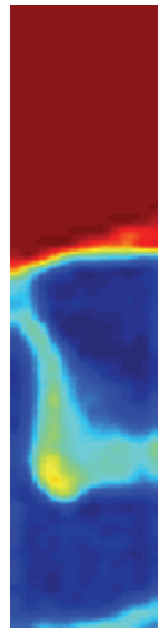

$0.273 \mathrm{~s}$

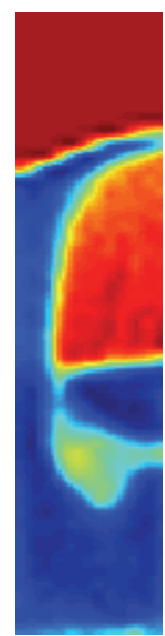

$0.117 \mathrm{~s}$

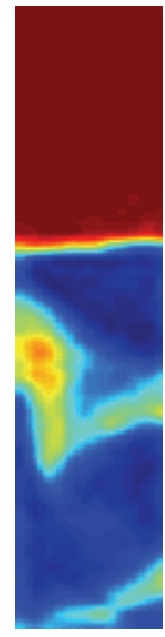

$0.312 \mathrm{~s}$

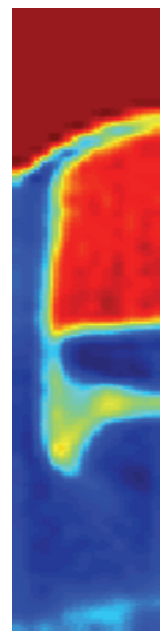

$0.156 s$

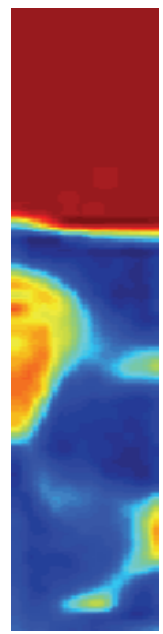

$0.351 \mathrm{~s}$

Figure 7: Voidage field for configuration (E) bed height $120 \mathrm{~mm}$ (36960 particles) at $U / U_{m f}=2.0$; bubble formation $(0 \mathrm{~s})$, bubbles coalescence $(0.078 \mathrm{~s})$, slug appearance $(0.117 \mathrm{~s})$ and bubble eruption $(0.234 \mathrm{~s})$ can be identified; red colour shows completely void regions; blue and intermediate shades show the 2 phase medium with dark blue being the most densely packed with particles

In deeper bed as shown as configuration D, E and F (Figure 3); it has been observed that more than one bubble can exist in the bed at any given time. These bubbles coalesce making larger bubbles. In some cases the bubble size became large enough to form a slug instead of a bubble. This behaviour becomes more prominent as the height of the bed (number of particles) is increased. Usually, round nose slugs are observed in configuration D and E. In configuration F, flat nose slugs were found in some instances.

Similarly, the voidage field of a wider bed (configuration G in Figure 3) is plotted as shown in Figure 8.

In the case of a wider bed (configuration $\mathrm{G}$ ), it is observed that there are many bubbles present in the bed at the same time (Figure 8). In addition, bubbles coalesce and form larger bubbles, but no slugs form as was observed in taller beds, cases (D, E and F). Furthermore, because of the larger width, two different streams of bubbles can be observed on the right and left sides of the bed. 


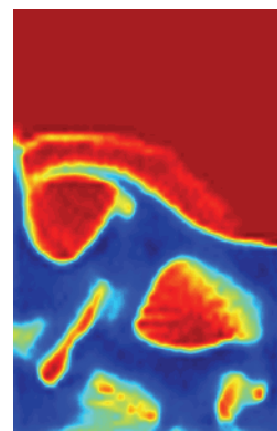

$0 \mathrm{~s}$

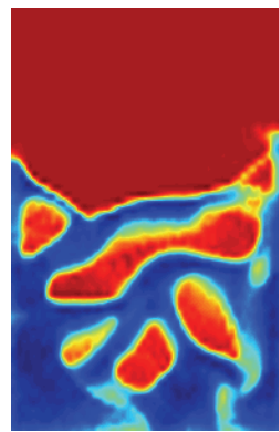

$0.195 \mathrm{~s}$

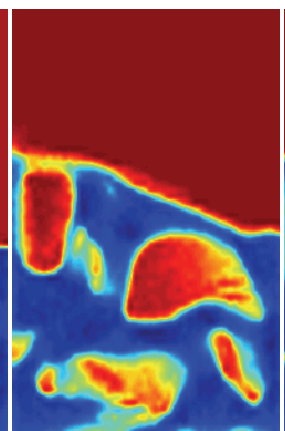

$0.039 \mathrm{~s}$

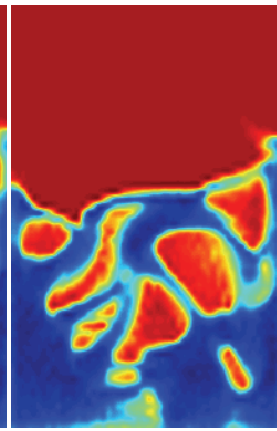

$0.234 \mathrm{~s}$

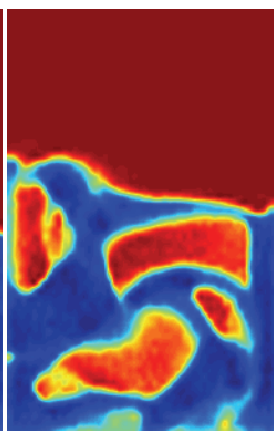

$0.078 \mathrm{~s}$

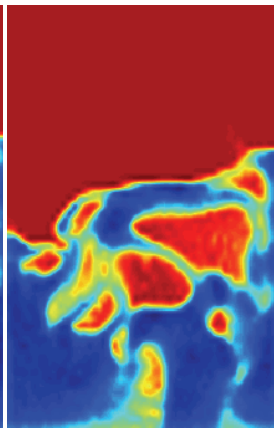

$0.273 \mathrm{~s}$

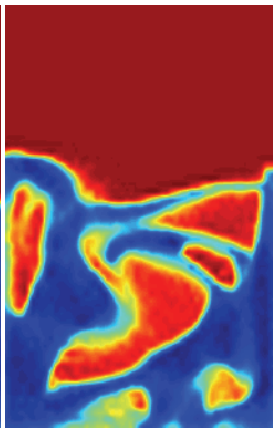

$0.117 \mathrm{~s}$

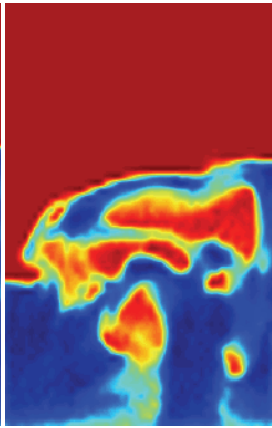

$0.312 \mathrm{~s}$

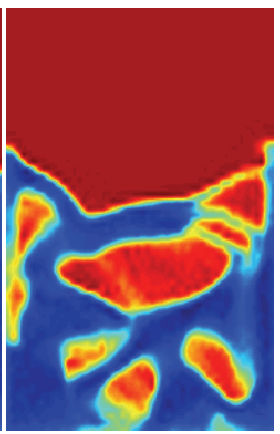

$0.156 s$

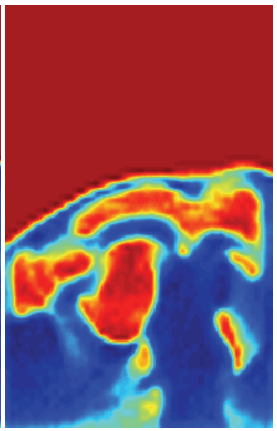

$0.351 \mathrm{~s}$

Figure 8: Voidage field for $(G) 120 \mathrm{~mm}$ bed height (147840 particles) for $U / U_{m f}=2.0$; Most of the bubbling bed phenomenon like bubbles formation, bubbles coalescence and eruption can be noted; red colour shows the completely void regions, blue and intermediate shades show the 2 phase medium with dark blue showing the regions most densely packed with particles

\section{EXPERIMENTAL RESULTS}

Fluidized beds were analysed experimentally in two ways: (1) using a camera for visual measurements and (2) using pressure sensors at various locations of the bed to record voltages and convert them into pressure data via a calibration curve. Images taken with the camera were converted into black and white as shown in Figure 5.

The configurations for the experiment were similar to those used for simulations shown in Figure 3. It was found that configuration A was too small to be analysed by the experimental methods. Also for configuration F the field of view of the camera was too small to visualize the entire bed. In order to develop a comparison between simulation and experiment, experimental results from configurations B, E and $\mathrm{G}$ results are discussed below. Figure 9 shows the visual experimental results observed for at $U / U_{m f}=2.0$.

Generally, the bed contains only one bubble at any time. Predominantly, round nose bubbles were observed. The bubbles are large, but the bed is too short for well-developed slugs to form. Similar experimental results were observed in fluidized beds with lower heights (configurations B and C).

The visual experimental results for configuration $\mathrm{E}$ at $U / U_{m f}=2.0$ are shown in Figure 10 .

In deeper beds (configurations D, E and F), slugging is observed as shown in Figure 10. Predominantly round nose slugs are seen in configurations D and E. In configuration F, flat nose slugs can sometimes be seen. Configuration $\mathrm{G}$ at $U / U_{m f}=2.0$ is shown in Figure 11. 


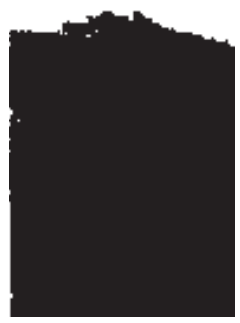

$0 \mathrm{~s}$

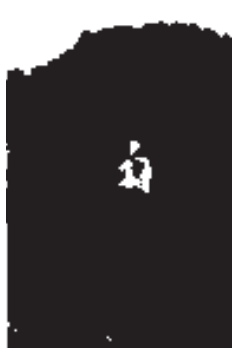

$0.165 \mathrm{~s}$

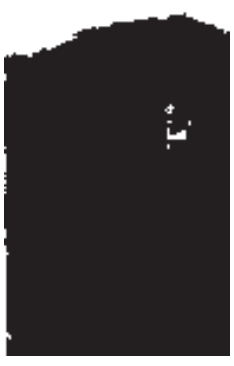

$0.033 \mathrm{~s}$

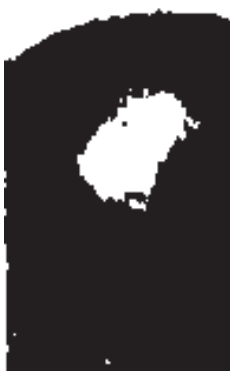

$0.198 \mathrm{~s}$

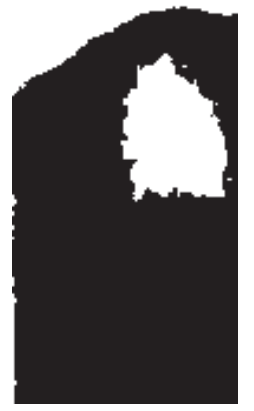

$0.066 \mathrm{~s}$

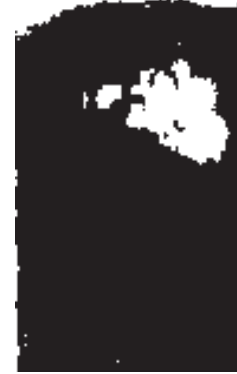

$0.231 \mathrm{~s}$

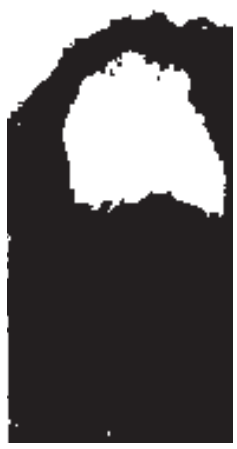

$0.099 \mathrm{~s}$

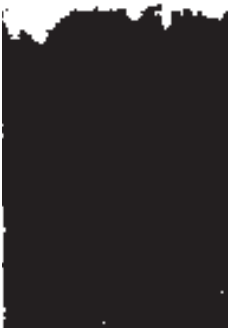

$0.264 \mathrm{~s}$

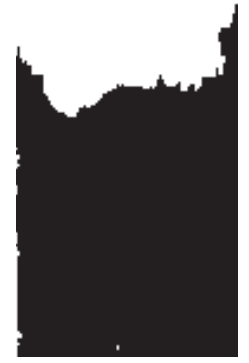

$0.132 \mathrm{~s}$

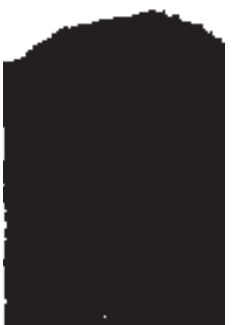

$0.297 \mathrm{~s}$

Figure 9: Black and white images for configuration (B) with bed height $=15 \mathrm{~mm}(9240$ particles) at $U / U_{m f}=2.0$; bubble appearance $(0.066 \mathrm{~s})$ and bubble eruption $(0.132 \mathrm{~s})$ can be identified

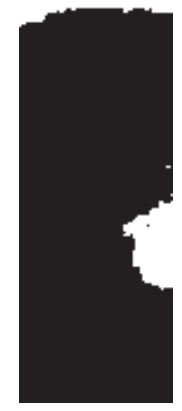

$0 \mathrm{~s}$

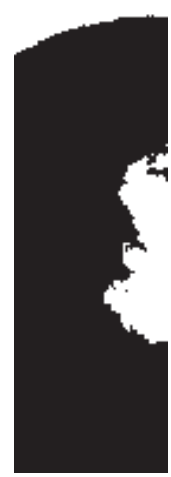

$0.033 \mathrm{~s}$

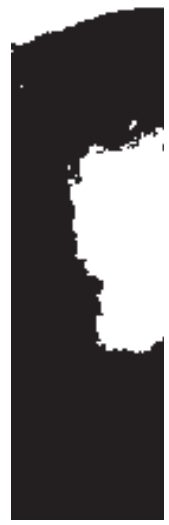

$0.066 \mathrm{~s}$

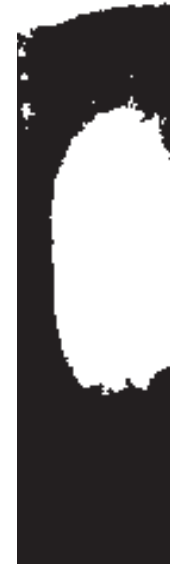

$0.099 \mathrm{~s}$

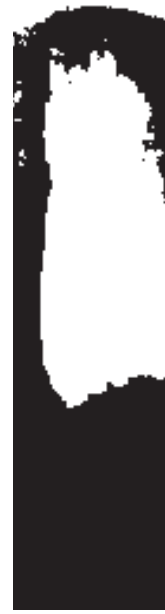

$0.132 \mathrm{~s}$

Figure 10:...Continued 


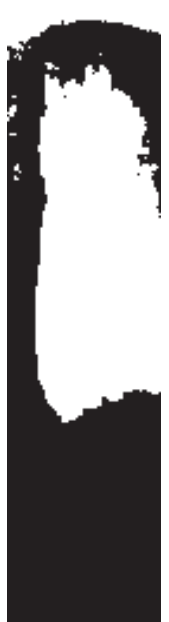

$0.165 \mathrm{~s}$

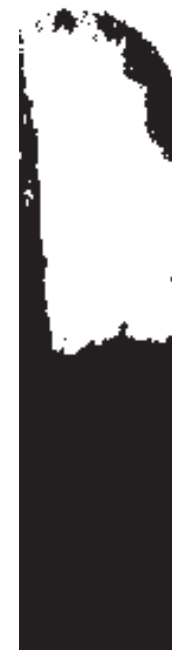

$0.198 \mathrm{~s}$

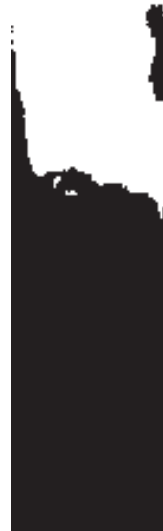

$0.231 \mathrm{~s}$

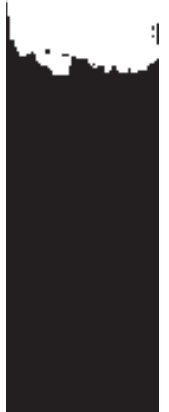

$0.264 \mathrm{~s}$

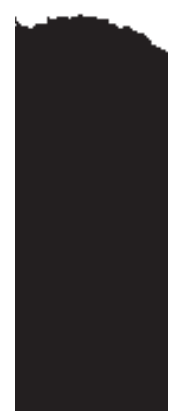

$0.297 \mathrm{~s}$

Figure 10: Black and white images of configuration $(E)$ with bed height $=120 \mathrm{~mm}$ (36960 particles) at $U / U_{m f}=2.0$; slug appearance $(0.099 \mathrm{~s})$ and slug eruption (0.198 s) can be identified

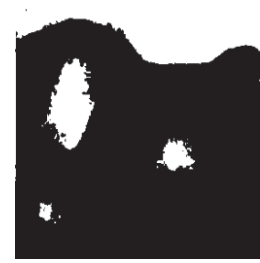

$0 \mathrm{~s}$

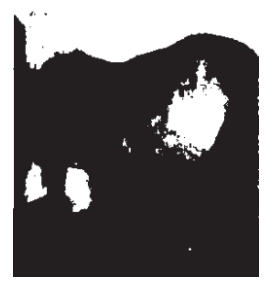

$0.165 \mathrm{~s}$

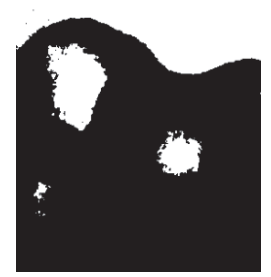

$0.033 \mathrm{~s}$

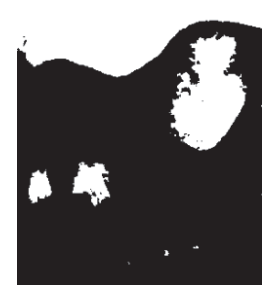

$0.198 \mathrm{~s}$

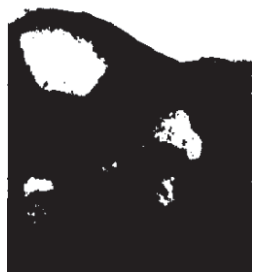

$0.066 \mathrm{~s}$

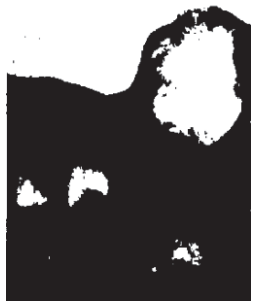

$0.231 \mathrm{~s}$

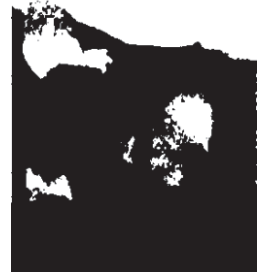

$0.099 \mathrm{~s}$

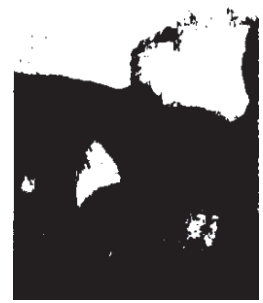

$0.264 \mathrm{~s}$

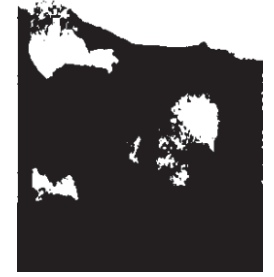

$0.132 \mathrm{~s}$

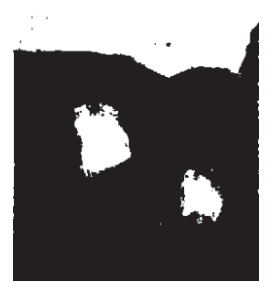

$0.297 \mathrm{~s}$

Figure 11: Black and white images of configuration $(G)$ bed height $=120 \mathrm{~mm}(147840$ particles) at $U / U_{m f}=2.0$

In this configuration more than one bubble is present in the fluidized bed at any given time. Two streams of bubbles formed, one at each side of the bed. In some instances, bubbles coalesced to form larger bubbles; however, no slugging was observed in this configuration, as was observed in configurations D, E and F.

\section{COMPARISON OF CFD-DEM AND EXPERIMENTAL RESULTS:}

In this section, the results from CFD-DEM simulation and experiments are compared. The bed expansion results are taken by averaged results over a period of time. It was observed that bed expansion varies while bubbling is occurring. The bed heights noted for each configuration are given in Table 2 .

A reasonable agreement has been found in CFD-DEM and experimental results for bed 
expansion height. The maximum error of $20 \%$ is noted in smallest bed where bed expansion has been approximated. Additionally, the percentage difference decreases as bed size increases.

Table 2: The comparison of bed expansion observed via CFD-DEM simulations and experiments

\begin{tabular}{|c|c|c|c|c|}
\hline Configuration & Number of & Bed expansion & Bed expansion & \% Difference \\
\hline & $\begin{array}{l}\text { Particles (un- } \\
\text { fluidized bed } \\
\text { height in } \mathrm{mm} \text { ) }\end{array}$ & $\begin{array}{c}\text { (mm) observed via } \\
\text { CFD-DEM } \\
\text { simulations }(X)\end{array}$ & $\begin{array}{l}(\mathrm{mm}) \text { observed via } \\
\text { Experiments }(\mathrm{Y})\end{array}$ & $=\frac{|X-Y| * 100}{Y}$ \\
\hline A & 4620 (15) & 24 & 20 (Approx.) & $20 \%$ \\
\hline B & $9240(30)$ & 58 & 50 & $16 \%$ \\
\hline $\mathrm{C}$ & $18480(60)$ & 91 & 100 & $9 \%$ \\
\hline D & $27720(90)$ & 148 & 140 & $5 \%$ \\
\hline$E$ & 36960 (120) & 206 & 210 & $2 \%$ \\
\hline $\mathrm{F}$ & $73920(240)$ & 422 & 410 (Approx.) & $3 \%$ \\
\hline G (wide bed) & $147840(120)$ & 175 & 185 & $6 \%$ \\
\hline
\end{tabular}

\section{CONCLUSION}

The CFD-DEM simulation was used to study the phenomenon of bubbling in the fluidized beds. In order to validate the results, an experimental technique was established. The results achieved via experiments and simulations are compared and discussed. With the increase of bed height (number of particles), a transition from bubbling to slugging bed can be observed. A further increase of particles changes the shape of slug from round to flat nose. Similar observations supporting this assertion were made via simulations and experiments. Expansions in different sizes of fluidized bed measured by both CFD-DEM simulations and experiments are found in close proximity.

\section{REFERENCES}

[1] Davidson, J.F. and D. Harrison, Fluidized Particles (first ed.). 1963: Cambridge University Press, Cambridge, New York.

[2] Kunii, D. and O. Levenspiel, Fluidization Engineering. 1991: Butterworth-Heinemann.

[3] Davies, R.M. and G. Taylor, The Mechanics of Large Bubbles Rising through Extended Liquids and through Liquids in Tubes. Proceedings of the Royal Society of London. Series A. Mathematical and Physical Sciences, 1950. 200(1062): p. 375-390.

[4] Stewart, P.S.B. and J.F. Davidson, Slug flow in fluidised beds. Powder Technology, 1967. 1(2): p. 61-80.

[5] Rudolph, V. and M.R. Judd. Circulation and slugging in a fluid bed gasifier fitted with a draft tube. in Circulating Fluidized Bed Technology. 1985. Pergamon Press, New York.

[6] Yates, J.G., Fundamentals of fluidized-bed chemical processes. 1983, London: Butterworths.

[7] Müller, C.R., et al., Oscillations in gas-fluidized beds: Ultra-fast magnetic resonance imaging and pressure sensor measurements. Powder Technology, 2007. 177(2): p. 87-98.

[8] Lim, K.S. and P.K. Agarwal, Bubble velocity in fluidized beds: The effect of non-vertical bubble rise on its measurement using submersible probes and its relationship with bubble size. Powder Technology, 1992. 69(3): p. 239-248.

[9] Geldart, D., Types of gas fluidization. Powder Technology, 1973. 7(5): p. 285-292.

[10] MATLAB®, version 7.14.0.739. 2012, The MathWorks Inc.: Natick, Massachusetts.

[11] Anderson, T.B. and R. Jackson, Fluid Mechanical Description of Fluidized Beds. Equations of Motion. Industrial \& Engineering Chemistry Fundamentals, 1967. 6(4): p. 527-539.

[12] Crowe, C.T., M. Sommerfeld, and Y. Tsuji, Multiphase Flows With Droplets and Particles. 1998: CRC Press.

[13] Khawaja, H., et al., Quantitative Analysis of Accuracy of Voidage Computations in CFD-DEM Simulations. The Journal of Computational Multiphase Flows, 2012. 4(2): p. 183-192. 
[14] Patankar, S.V., Numerical Heat Transfer and Fluid Flow. 1980: Taylor \& Francis.

[15] Anderson, J.D., Computational fluid dynamics: the basics with applications. 1995: McGraw-Hill.

[16] Courant, R., K. Friedrichs, and H. Lewy, Über die partiellen Differenzengleichungen der mathematischen Physik. Mathematische Annalen, 1928. 100(1): p. 32-74.

[17] Hirsch, C., Numerical Computation of Internal and External Flows: Fundamentals of Computational Fluid Dynamics. 2007: Elsevier/Butterworth-Heinemann.

[18] Ergun, S., Fluid flow through packed columns. Chem. Process Eng. London, 1952. 1: p. 89-94.

[19] Wen, C.Y. and Y.H. Yu, Mechanics of fluidization. Chem. Eng. Prog. Symp. Series., 1966(62): p. $100-111$.

[20] Di Felice, R., The voidage function for fluid-particle interaction systems. International Journal of Multiphase Flow, 1994. 20(1): p. 153-159.

[21] Beetstra, R., M.A. van der Hoef, and J.A.M. Kuipers, Numerical study of segregation using a new drag force correlation for polydisperse systems derived from lattice-Boltzmann simulations. Chemical Engineering Science, 2007. 62(1-2): p. 246-255.

[22] Müller, C.R., et al., Granular temperature: Comparison of Magnetic Resonance measurements with Discrete Element Model simulations. Powder Technology, 2008. 184(2): p. 241-253.

[23] Gear, C.W., Numerical initial value problems in ordinary differential equations. 1971: Prentice-Hall.

[24] Hairer, E., S.P. Nørsett, and G. Wanner, Solving Ordinary Differential Equations: Nonstiff problems. 1993: Springer.

[25] van der Hoef, M.A., et al., Numerical simulation of dense gas-solid fluidized beds: A multiscale modeling strategy, in Annual Review of Fluid Mechanics. 2008, Annual Reviews: Palo Alto. p. 47-70.

[26] Cundall, P.A. and O.D.L. Strack, A discrete numerical model for granular assemblies. Geotechnique, 1979. 29(1): p. 47-65.

[27] Third, J., et al., Tangential velocity profiles of granular material within horizontal rotating cylinders modelled using the DEM. Granular Matter, 2010. 12(6): p. 587-595.

[28] Tsuji, Y., T. Tanaka, and T. Ishida, Lagrangian numerical simulation of plug flow of cohesionless particles in a horizontal pipe. Powder Technology, 1992. 71(3): p. 239-250.

[29] Tsuji, Y., T. Kawaguchi, and T. Tanaka, Discrete particle simulation of two-dimensional fluidized bed. Powder Technology, 1993. 77(1): p. 79-87.

[30] van der Hoef, M.A., M. van Sint Annaland, and J.A.M. Kuipers, Computational fluid dynamics for dense gas-solid fluidized beds: a multi-scale modeling strategy. Chemical Engineering Science, 2004. 59(22-23): p. 5157-5165.

[31] Hertz, H., Über die Berührung fester elastischer Körper. J. Reine Angew. Mat., 1882(92): p. $156-171$.

[32] Mindlin, R.D. and H. Deresiewicz, Elastic Spheres in Contact Under Varying Oblique Forces. J. of Appl. Mech., 1953. 20: p. 327.

[33] Khawaja, H. and K. Parvez, Validation of normal and frictional contact models of spherical bodies by FEM analysis. The International Journal of Multiphysics, 2010. 4(2): p. 175-185.

[34] Baryshev, G., H. Khawaja, and M. Moatamedi, Optimization of Particle Search Algorithm for CFD-DEM Simulations. The Journal of Computational Multiphase Flows, 2013. 5(3): p. 223-230.

[35] Khawaja, H., CFD-DEM Simulation of Minimum Fluidisation Velocity in Two Phase Medium. The International Journal of Multiphysics, 2011. 5(2): p. 89-100.

[36] Khawaja, H. and S. Scott, CFD-DEM Simulation of Propagation of Sound Waves in Fluid Particles Fluidised Medium. The International Journal of Multiphysics, 2011. 5(1): p. 47-60.

[37] Boyce, C.M., et al., Novel fluid grid and voidage calculation techniques for a discrete element model of a 3D cylindrical fluidized bed. Computers \& Chemical Engineering, 2014. 65: p. 18-27. 